\title{
Influence of Fiber on Anti-corrosion and Freeze-thaw Durability of Airport Deicing Platform
}

\author{
MA Daoxun ${ }^{1,2, a}$, LIU Yan ${ }^{1,2, b}$, SU Xin ${ }^{1,2}$, LAI Yong ${ }^{1,2, c}$, WANG Peng ${ }^{1,2}$ \\ ${ }^{1}$ China Airport Construction Group Corporation, Beijing, 100101, China \\ ${ }^{2}$ Beijing Super-Creative Technology Co., LTD, Beijing, 100621, China \\ adaoxunma@126.com, ${ }^{b}$ tjdoc@tom.com, ${ }^{\mathrm{C}} \mathrm{Izg} 2076 @ 163 . c o m$
}

Keywords: Fiber, Airport deicing platform, Corrosion, Freeze-thaw

Abstract. Fiber is capable of improving the corrosion resistance and freeze-thaw durability of concrete of airport deicing platform. After 300 freeze-thaw cycles, the relative dynamic modulus of plain concrete is reduced to $73.46 \%$, and the relative dynamic modulus of fiber concrete is about $80 \%$, that is, the fiber has a positive influence on the frost resistance of concrete. In addition, the durability of fiber reinforced concrete is better than that of plain concrete under the same test conditions as the corrosion cycles and freeze-thaw cycles.

\section{Introduction}

Fiber reinforced concrete is cement based composite material which is formed by using concrete as the base material and uniformly mixed with various non continuous short fibers ${ }^{[1-3]}$. Fiber mainly through the physical and mechanical effects improving the concrete internal structure doesn't change the chemical properties of various materials in the concrete itself, thus it will not damage the durability of concrete. Fiber plays a role in the following three aspects: crack arrest, strengthening and toughening ${ }^{[4-7]}$. Therefore, comparing with plain concrete there are different degrees of improvement in crack resistance ${ }^{[3,8-9]}$, bending resistance, impact resistance and anti-fatigue properties for the fiber concrete which are widely used in various fields of bridges, airports, highways, tunnels, water conservancy ${ }^{[10-12]}$.

Recently at home and abroad for the effect of fiber on the corrosion performance and the coupled action of corrosion and freeze-thaw durability basically is not involved, hence in this paper, it have been done on the research of fiber related aspects.

\section{Experiments}

In this paper, cellulosic fiber which has hydrophilic property is chosen, and its surface has a strong grip force and it is easily dispersed into the fiber monofilament, and it can effectively improve the overall performance of concrete. Table 1 is the main parameters of cellulose fibers. Table 2 is the mix design parameters of concrete. Table 3 is given in ASTM C672 for assessing the apparent properties of concrete. 
Table 1 Main Parameters of Fiber

\begin{tabular}{|c|c|c|c|c|c|c|c|c|}
\hline \multicolumn{6}{|c|}{ Average fiber length (mm) } & \multicolumn{3}{|c|}{2.1} \\
\hline \multicolumn{6}{|c|}{ Density $\left(\mathrm{g} / \mathrm{cm}^{3}\right)$} & \multicolumn{3}{|c|}{1.109} \\
\hline \multicolumn{6}{|c|}{ Average fiber diameter $(\mu \mathrm{m})$} & \multicolumn{3}{|c|}{18} \\
\hline \multicolumn{6}{|c|}{ Tensile $(\mathrm{MPa})$} & \multicolumn{3}{|c|}{960} \\
\hline \multicolumn{9}{|c|}{ Table 2 Mix Design Parameters of Concrete } \\
\hline No. & Cement & $\begin{array}{l}\text { Water } \\
\text { cement } \\
\text { ratio }\end{array}$ & Water & Sand & $\begin{array}{c}\text { Coarse } \\
\text { aggregate } \\
(20 \square 40 \mathrm{~mm})\end{array}$ & $\begin{array}{c}\text { Coarse } \\
\text { aggregate } \\
(5 \square 20 \\
\mathrm{mm})\end{array}$ & Admixture & $\begin{array}{l}\text { Fiber } \\
/ \mathrm{kg} \cdot \mathrm{m}^{-3}\end{array}$ \\
\hline A & 330 & 0.4 & 132 & 607 & 849.6 & 566.4 & $2 \%$ & 0 \\
\hline $\mathrm{B}$ & 330 & 0.4 & 132 & 607 & 849.6 & 566.4 & $2 \%$ & 0.9 \\
\hline $\mathrm{C}$ & 330 & 0.4 & 132 & 607 & 849.6 & 566.4 & $2 \%$ & 1.2 \\
\hline $\mathrm{D}$ & 330 & 0.4 & 132 & 607 & 849.6 & 566.4 & $2 \%$ & 1.5 \\
\hline $\mathrm{E}$ & 330 & 0.4 & 132 & 607 & 849.6 & 566.4 & $2 \%$ & 1.7 \\
\hline \multicolumn{9}{|c|}{ Table 3 Classification of Apparent Properties of Concrete } \\
\hline \multicolumn{2}{|c|}{ Level } & \multicolumn{7}{|c|}{ Surface condition } \\
\hline \multicolumn{2}{|r|}{0} & \multicolumn{7}{|c|}{ no spalling } \\
\hline \multicolumn{2}{|r|}{1} & \multicolumn{7}{|c|}{ slight spalling(deepest $3 \mathrm{~mm}$, no coarse aggregate exposed) } \\
\hline \multicolumn{2}{|r|}{2} & \multicolumn{7}{|c|}{ slight to moderate spalling } \\
\hline & 3 & \multicolumn{7}{|c|}{ moderate spalling (part coarse aggregate exposed) } \\
\hline & 4 & \multicolumn{7}{|c|}{ moderate to severe spalling } \\
\hline & 5 & \multicolumn{7}{|c|}{ severe spalling (entire aggregate surface exposed) } \\
\hline
\end{tabular}

\section{Results and Discussion}

Effect of fiber content on freeze-thaw durability of concrete. Fig. 1 is the influence law of relative dynamic elastic modulus of concrete with 300 cycles of freeze-thaw and different fiber content $(0 \sim 1.7$ $\mathrm{kg} / \mathrm{m}^{3}$ ), the results show that the addition of fiber can improve the frost-resisting durability of concrete.

With freeze-thaw cycles being conducted, the relative dynamic elastic modulus of each airport concrete were gradually decreased, and as the fiber content is $0.9 \mathrm{~kg} / \mathrm{m}^{3}, 1.2 \mathrm{~kg} / \mathrm{m}^{3}, 1.5 \mathrm{~kg} / \mathrm{m}^{3}$ and $1.7 \mathrm{~kg} / \mathrm{m}^{3}$ respectively, the relative dynamic elastic modulus of concrete were $80.21 \%, 80.28 \%$, $81.32 \%$ and $82.17 \%$, which all being higher than that of OPC (73.64\%). When fiber content is $0 \sim 1.7$ $\mathrm{kg} / \mathrm{m} 3$ there is no big difference between the influence of fiber content on relative dynamic elastic modulus of the concrete, that means fiber can improve the frost-resisting durability of concrete. 


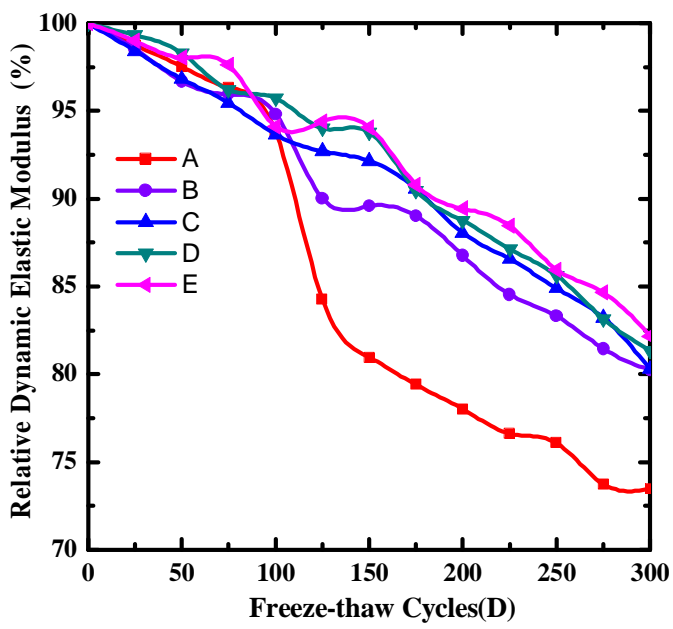

Fig.1 Relative dynamic modulus with freeze-thaw cycles under different fiber content

Effect of fiber on apparent damage of concrete under single corrosive environment. The appearance corrosion characteristics of OPC (A) and HPC-FR (fiber concrete) after 50 corrosion cycles of $100 \%$ aircraft deicing fluid is presented in Fig.2. After the corrosion of aircraft deicing fluid the apparent damage of OPC is more obvious than that of HPC-FR. The surface of OPC presents a network crack, while the HPC-FR does not exhibit a continuous crack tendency. From the point of view of surface corrosion resistance evaluation standard of concrete, the corrosion resistance grades of HPC-FR and OPC are 0 and 1 respectively. Therefore, the concrete with greater corrosion resistance in corrosion liquid is HPC-FR.

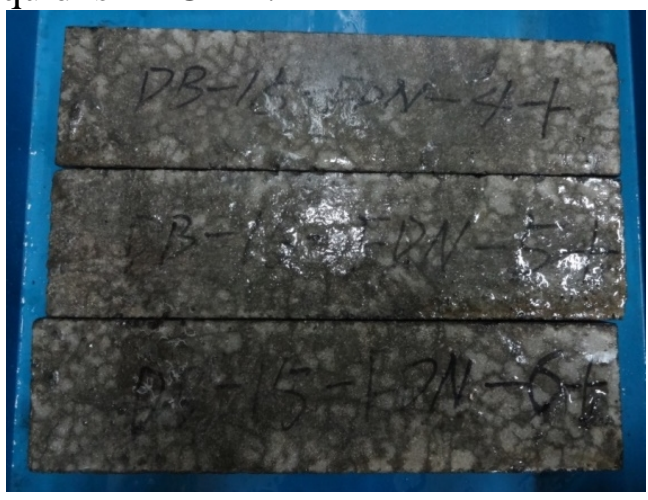

(a) OPC

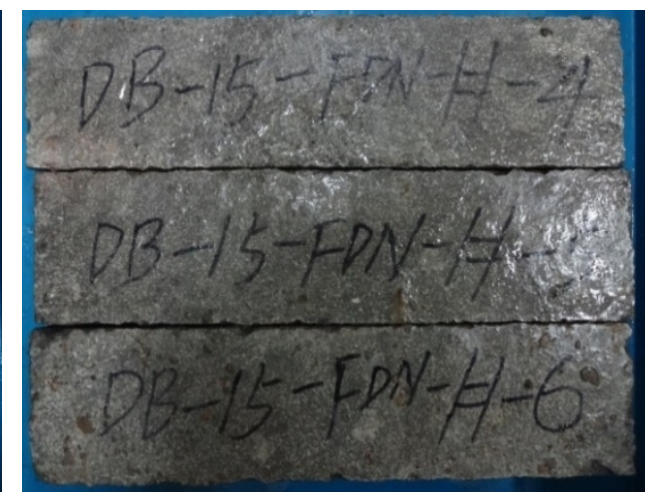

(b) HPC-FR

Fig. 2 Appearance corrosion characteristics of after 50 corrosion cycles

Effect of Fiber on durability of concrete with corrosion cycles. The effect of fiber on the corrosion resistance of concrete is showed at Fig.3. After 50 corrosion cycles, the mass loss rate of HPC-FR is less than OPC, and its relative dynamic elastic modulus is greater than OPC. In a single corrosive environment, fiber has an improved effect on the durability of concrete.

For mass loss rate, HPC-FR and OPC are 0 and $0.10 \%$ respectively after the 50 corrosion cycles, i.e. HPC-FR < OPC. Basically, during the whole corrosion cycles the weight of HPC-FR is increasing, while for OPC in addition to corrosion cycle of 35 times there is a large weight fluctuation, most of the time it shows spalling process and weight reduction; for the relative dynamic elastic modulus, HPC-FR and OPC are $96 \%$ and 90\% respectively, which is HPC-FR > OPC. Overall, according to the mass loss and relative dynamic elastic modulus, the fiber plays a positive role in improving the durability damage under low temperature corrosion environment. 


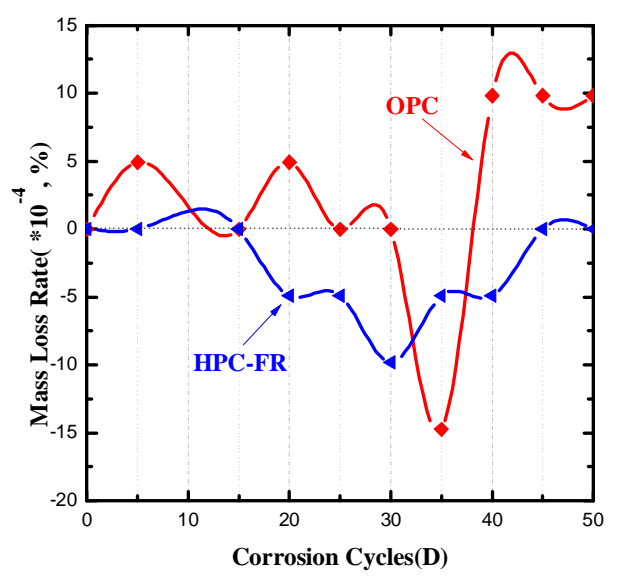

(a) Mass Loss Rate

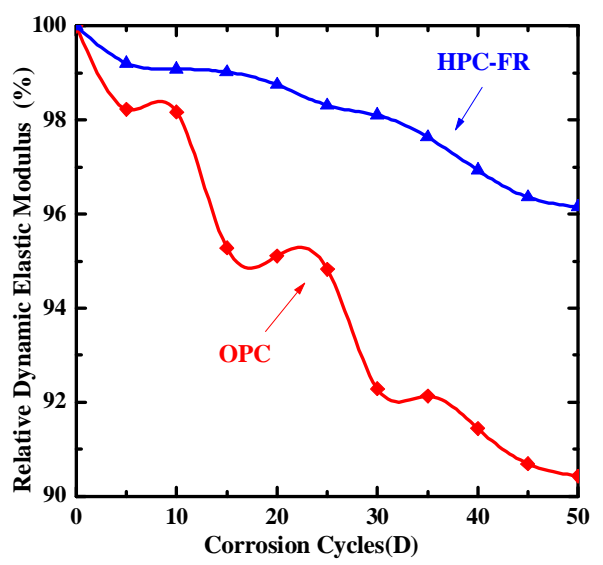

(b) Relative Dynamic Modulus

Fig. 3 Effect of Fiber on Corrosion Resistance of Concrete

Effect of fiber on durability of concrete with coupling effect of corrosion and freeze-thaw. Fig. 4 shows the change law of relative dynamic elastic modulus for OPC and HPC-FR under the corrosion cycle, freeze-thaw cycle, coupling effect of corrosion and freeze-thaw cycle. For the relative dynamic elastic modulus under corrosion cycles HPC-FR is $6 \%$ higher than OPC, under freeze-thaw cycles HPC-FR is 7\% higher than OPC; under the coupling effect of corrosion cycle and freeze-thaw cycle, HPC-FR is $15 \%$ higher than OPC. Therefore, whether it's a single durable environment or a coupling effect, the relative dynamic modulus of HPC-FR is higher than that of OPC.

For the relative dynamic elastic modulus of OPC, after 300 times of freeze-thaw cycle it's $73.46 \%$, after 50 times of corrosion cycle it's $90.43 \%$, after the coupling effect of corrosion cycle (50 times) and freeze-thaw cycle (300 times) it's $52.68 \%$, that is, the dynamic elastic modulus decreases by $9.57 \%$ due to corrosion cycle, decreasing by $26.54 \%$ due to freeze-thaw cycle, a total of the two is $36.11 \%$, but due to coupling effect the dynamic elastic modulus decreases by $47.32 \%$, which means for OPC the damage of coupling effect is greater than the sum of two single damage.

For the relative dynamic elastic modulus of HPC-FR, after 300 times of freeze-thaw cycle it's $80.28 \%$, after 50 times of corrosion cycle it's $96.15 \%$, after the coupling effect of corrosion cycle (50 times) and freeze-thaw cycle (300 times) it's $67.49 \%$, that is, the dynamic elastic modulus decreases by $3.85 \%$ due to corrosion cycle, decreasing by $19.72 \%$ due to freeze-thaw cycle, a total of the two is $23.57 \%$, but due to coupling effect the dynamic elastic modulus decreases by $32.51 \%$, which means for HPC-FR the damage of coupling effect is greater than the sum of two single damage.

So no matter what kinds of concrete, the coupling effect has more negative influence on the durability damage than the sum of two single damages; no matter from which point of view, fiber has positive effect on improving the durability of concrete. 


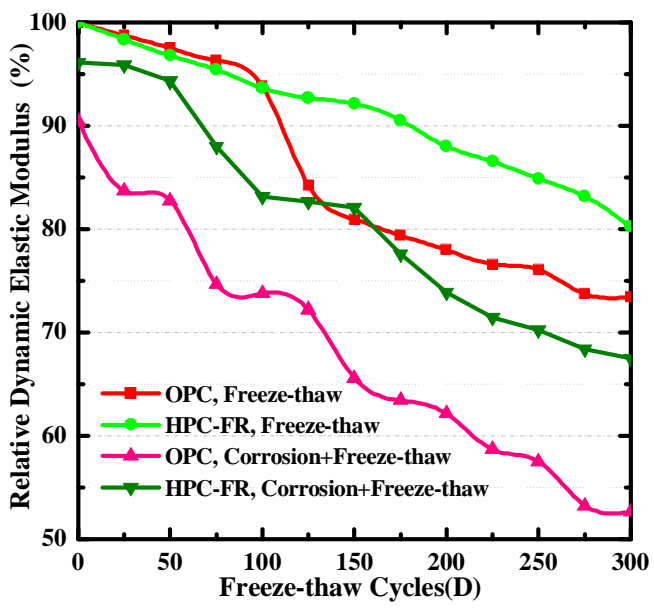

Fig.4 Relative dynamic elastic modulus of concrete under different environment

Analysis of the influence of fiber on the performance of concrete. The unique cavity structure of fiber is able to buff the volume expansion caused by frost heave in the inner capillary of concrete, on the other hand, the moisture adsorbed in the fiber is capable of promoting the hydration of cement more fully and completely in the process of hydration of concrete, thereupon then greatly decreasing the porosity, increasing the density of concrete and the difficulty of external moisture entering interior of concrete.

Fiber is able to be uniformly dispersed in the concrete, overlapping each other to form three-dimensional space network structure, which can effectively improve the early cracking caused by shrinkage of concrete and reduce the early damage and internal defects, and after concrete being freeze-thaw cracking, the fibers play a bridging role in inhibiting concrete spalling; because of fiber reinforcing the toughness of concrete, it can effectively resist the periodic repeated stress effect during freeze-thaw cycles; due to the incorporation of fiber cutting off the capillary water channel of concrete, the flow length of free water is shortened during freeze-thaw cycle, according to the hypothesis of hydrostatic pressure, the probability that the flow length of free water is greater than its critical value becomes smaller, resulting in that the water pressure exceeding the ultimate tensile strength of material will also reduce the probability of damage. Hence, incorporating a certain amount of fiber has ability to improving the corrosion resistance and freeze-thaw durability of concrete in de-icing fluid.

\section{Conclusions}

The incorporation of fiber has a positive influence on improving the frost resistance of concrete, meanwhile, enhancing the anti-corrosion durability of airport deicing concrete.

With the same test condition, no matter in the corrosion cycle, freeze-thaw cycle or coupling effect, the relative dynamic elastic modulus of HPC-FR is higher than OPC.

The cavity structure of fiber itself is able to buff the volume expansion caused by frost heave in the inner capillary of concrete; the formed three-dimensional space network structure of fiber can effectively improve the early cracking caused by shrinkage of concrete and reduce the early damage and internal defects.

\section{Acknowledgements}

This work is financially supported by the Major Projects of Civil Aviation Administration (Grant Nos.MHRD20130109), Civil Aviation Science and Technology Project (Grant Nos.MHRD20150225) and Capital Airport Holding Co. Science and Technology Project (Research on the key technology of new materials about high durability and high crack resistance airport pavement). 


\section{References}

[1] Swamy R.N, Mangat P.S, Rao C.V.S.K. The mechanics of fiber reinforcement of cement matrices.ACI Structure Journal, 1974(44): 1 28

[2] Graybeal B, Tanesi J. Durability of an ultrahigh-performance concrete. Journal of Material in Civil Engineering, 2007, 19(10): 848 854

[3] Romualdi J P, Batson G B, Mechanics of crack arrest in concrete. Journal of the Engineering Mechanics Division, 2015, 3(89): 147 168

[4] Holschemacher K, Mueller T, Ribakov Y. Effect of steel fibres on mechanical properties of high-strength concrete. Material \& Design, 2010,31(5):2604 2615

[5] Ma Haoxia, Yu Hongfa,etc. Chemical corrosion of cement concrete under the action of airport pavement deicer. Journal of Architecture and Civil Engineering, 2012, 29(2):61 66

[6] Bai Kang. Research on freezing-thawing durability of concrete subjected to airfield pavement deicer. Nanjing: Nanjing University of Aeronautics, 2009

[7] Yang Quanbing, Zhu Beirong. Effect of steel fiber on the deicer-scaling resistance of concrete. Cement and Concrete Research, 35(2005):2360 2363

[8] Xianming Shi, Laura Fay, Marijean M.Peterson, Michael Berry, Matthew Mooney. A FESEM/EDX investigation into how continuous deicer exposure affects the chemistry of Portland cement concrete. Construction and Building Materials, 25(2011):957 966

[9] M.C. Santagataa, M. Collepardib. The effect of CMA deicers on concrete properties. Cement and Concrete Research, 30(2000):1389 1394

[10]ASTM Standards. Standard Test Method for Scaling Resistance of Concrete Surfaces Exposed to Deicing Chemicals1 (ASTM C 672M-03.). Philadelphia, USA: American Society for Testing and Materials: 2012

[11]Mahmoud Nili, M. Zaheri. Deicer salt-scaling resistance of non-air-entrained roller-compacted concrete pavements. Construction and Building Materials, 25(2011):1671 1676

[12]Colin Giebson, Katrin Seyfarth, Jochen Stark. Influence of acetate and formate-based deicers on ASR in airfield concrete pavements. Cement and Concrete Research, 40(2010):537 545 